\title{
Using latent energy of water-ice phase change to reduce energy losses in buildings in cold climate
}

\author{
Gatis Žogla, Andra Blumberga, Kristaps Kašs \\ Institute of Energy Systems and Environment \\ Riga Technical University \\ Riga, Latvia
}

\begin{abstract}
Energy efficiency in buildings is a very important challenge that has to be faced in order to achieve the aims set by the new EU directive on Building energy efficiency encouraging nearly zero energy buildings. Unfortunately in countries with cold climate it is very hard to achieve this goal. The thickness of insulation needed to reach low energy consumption in cold climate is very big and in many cases it is not economically feasible. There is a need for new solutions for increasing building energy efficiency.

In this paper a new solution for increasing building energy efficiency is proposed. It is proposed to use the latent energy of water-ice phase change to reduce heat conduction losses through building envelope. The latent energy is recovered by using low potential heat source.

In this paper the validity of the proposed new solution is tested on a one dimensional scale - homogeneous infinite wall. The presented methodology is chosen to calculate systems operational efficiency throughout the whole year.
\end{abstract}

Keywords - energy efficiency, heat losses, water, phase change, water - ice, cold climate

\section{Nomenclature}

HTF - heat transfer fluid;

PCM - phase change material;

$t_{\text {am }}$-ambient temperature, ${ }^{\circ} \mathrm{C}$;

$t_{w \text { wall }}-$ water wall temperature, ${ }^{\circ} \mathrm{C}$;

$x$-fraction of latent heat used;

$t_{\text {beg }}$-temperature at which HTF enters heat exchanger, ${ }^{o} \mathrm{C}$;

$t_{\text {out }}$-temperature at which HTF exits heat exchanger, ${ }^{\circ} C$;

$t_{g r}-$ undisturbed ground temperature, ${ }^{\circ} \mathrm{C}$;

$\mathrm{m}^{\cdot}-$ mass flow rate, $\mathrm{kg} / \mathrm{s}$;

$q$-heat flux density, $\mathrm{W} / \mathrm{m}^{2}$;

$U$ - combined heat transfer coefficient, $W /\left(m^{2} K\right)$;

$\Delta T$-temperature difference between ambient and indoor air, $K$;

$Q_{h . l}-$ heat loss via building envelope, $W$;

$Q_{h . r .}-$ heat recovery via heat recovery unit, $W$;

h-enthalpy, $\mathrm{kJ} / \mathrm{kg}$;

$t_{h}$ - phase change temperature, ${ }^{\circ} \mathrm{C}$;

$\lambda$ - thermal conductivity of a building element, $W /(m K)$;

$N$ - number of homogeneous layers of building construction;

$\alpha_{i}$-internal heat convection coefficient, $W /\left(m^{2} K\right)$;

$\alpha_{o}$ - external heat convection coefficient, $W /\left(m^{2} K\right)$;

$\Delta x$ - thickness of a homogeneous layer, $\boldsymbol{m}$;

$T_{f r}$ - phase change temperature, ${ }^{o} \mathrm{C}$;

$\mathrm{T}_{1}$-water temperaturein the beginning, ${ }^{o} \mathrm{C}$;

$\boldsymbol{k}_{\mathrm{s}}$ - heat conductivity of water, $\mathrm{W} / \mathrm{mK}$;

$h$-heat transfer from surface, $W /\left(m^{2} K\right)$.

Index:

1 -at the starting point, before;

2 -at the finishing point, after;

\section{INTRODUCTION}

Heating and cooling loads account for a large fraction in the total yearly energy balance of a household. The biggest heat losses occur during the heating season, in which heating costs take up the largest fraction of total monthly energy bill. This is due to inadequate heat energy use or poorly insulated building envelope. Irrational heat energy use accounts not only for high energy costs for the consumers, but also for the higher energy production costs because of higher heat losses throughout the energy production process which increases the energy cost. Nowadays the question about cooling loads is also getting more and more substantial. Modern buildings are equipped with many complex electronic communication devices which are operating altogether and are emitting large amount of heat. Together with high rate of daily human attendance and solar radiation, this accounts for large amount of heat. It requires a lot of cooling power to drain day time excessive internal and external heat energy gains. Therefore it is crucial to learn new ways how to store and utilize when needed the free energy sources that are surrounding us geothermal, wind and sun. One of the most promising methods of heat energy storage can be achieved by utilizing the latent heat of phase change materials (PCM), which upon phase change can store large amounts of heat.

In literature a wide spectrum of phase change material usage throughout different sectors is described, starting from food packaging extending to thermal clothing and heat energy storage [1]. In most cases PCM applications are related to cooling processes. In buildings PCM's are used to reduce cooling loads. PCM's are integrated into different building structures to absorb excessive heat gains during the day time, thus preventing the building from overheating without any additional energy input. At nights the excessive heat is discharged by using free night time ventilation or cheaper electricity. This system shows promising results for implementation in climate conditions with high diurnal temperature fluctuations, mostly for Mediterranean climate conditions.

Evaporation of liquids on the building elements is another way of latent heat usage. In hot climate conditions for cooling purposes this phenomena is studied by $\mathrm{He}$ and Hoyano [2]. The objective of their study is to achieve naturally forced and cooled air circulation in the building. They propose to make a cavity into the building wall in which water and hot air from 
the outside could be circulated. The natural air flow is ensured by utilizing solar chimney principle. Hot air flow and heated wall in the one side of the cavity and water flow along the other wall of the cavity results in a water evaporation process. As a result the ambient hot air is cooled and a comfortable indoor temperature is achieved. The authors pointed out, that comfortable indoor conditions were achieved even when the solar heat flux was $200 \mathrm{~W} / \mathrm{m}^{2}$ and ambient temperature $40^{\circ} \mathrm{C}$. The relative humidity was recognized as the limiting factor. The acceptable indoor conditions were achieved when the relative humidity values were not higher than $50 \%$.

\section{Climate CONDITIONS IN LATVIA}

The average yearly outdoor air temperature in Latvia varies from +4.5 to $+6.7^{\circ} \mathrm{C}$. Monthly outdoor air temperatures vary from $-7.6{ }^{\circ} \mathrm{C}$ in January in Aluksne to $+16.9{ }^{\circ} \mathrm{C}$ in July in Riga (average monthly temperatures in Latvia vary by 24,5 ${ }^{\circ} \mathrm{C}$ ). Average monthly outdoor air temperatures in Latvia can be seen in Figure 1.

Figure 1 illustrates three cities: Riga (capital of Latvia), Aluksne (city with lowest average yearly outdoor air temperature in Latvia) and Liepaja (city with highest average yearly outdoor air temperature in Latvia).

The highest registered outdoor air temperature in Latvia was fixed in 4th of August in 1943 in Daugavpils when outdoor air temperature reached $+36.4{ }^{\circ} \mathrm{C}$. The lowest outdoor air temperature in Latvia was registered in 8th of February in 1956 when temperature in Daugavpils dropped down to -43.2 ${ }^{\circ} \mathrm{C}$. [3].

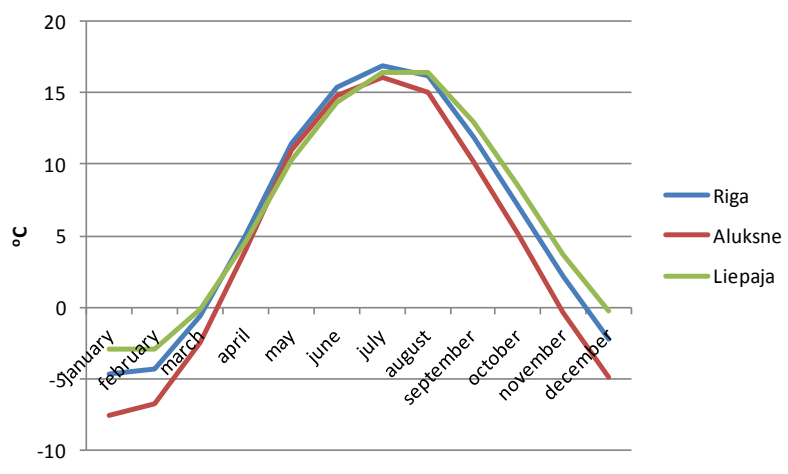

Fig. 1. Average monthly outdoor temperatures in Latvia [3]

\section{PARAMETERS WHICH INFLUENCE HEAT LOSSES FROM BUILDINGS}

Heating season usually starts when the outside temperature falls beneath a certain temperature, in Latvian climate conditions when the ambient air temperature falls beneath 8 ${ }^{\circ} \mathrm{C}$. At this point the temperature difference between the ambient and room temperatures are significant enough to cause substantial heat loss from the building envelope. If there are no additional heat sources within the building wall and we assume steady-state heat conduction, the heat losses through the building outer wall faced are described as temperature difference between the indoor temperature and ambient air temperature and the building wall thermal properties. The heat losses increase proportionally to the temperature difference increase between the ambient and indoor temperature as in:

$$
q=U \cdot \Delta T
$$

In Latvian climate conditions the temperature difference in winter months could be as high as $50 \mathrm{~K}$, which accounts for high heat losses through the buildings outer façade. From (1) it can be seen that there are two possible ways of heat loss reduction. The first one is the most traditional. As quoted by Mumovic and Santamouris - "The bases of energy-saving buildings is an efficient building envelope with all of the accompanying construction elements" [4]. By improving the building envelope insulation, the heat transfer coefficient $U$ is reduced, thus lowering the heat flux density and overall building heat losses. This is the most traditional way of heat loss reduction. The coefficient $U$ can be reduced by increasing the insulation material layer thickness or choosing an insulation material with lower thermal conductivity. This can be seen by (2) which describe the relation between insulation layer thickness, insulation material thermal conductivity and combined heat transfer coefficient [5]:

$$
\frac{1}{U}=\frac{1}{\alpha_{i}}+\sum_{i=1}^{N} \frac{\Delta x_{i}}{\lambda_{i}}+\frac{1}{\alpha_{0}}
$$

The other option of heat loss reduction is by reducing the temperature difference between the ambient and room temperatures which would also result as heat loss reduction. This is mostly done by decreasing the room temperature. If it is assumed, that combined heat transfer coefficient $U$ stays constant at all times, then it can be said that the lower the temperature between the two environments the lower the heat flux density. This can be shown by modifying (1):

$$
\frac{q_{2}}{q_{1}}=\frac{\Delta T_{2}}{\Delta T_{1}}
$$

In (3) it can be shown how many heat energy could be saved by lowering the room temperature by $1{ }^{\circ} \mathrm{C}$, in conditions, where other parameters stay constant.

However there is another way lowering the temperature difference between the two environments. It is not possible to change outdoor air temperature but it is possible to artificially set the temperature on the outer surface of building envelope. In this case, regardless of the actual outdoor air temperature, the temperature on the outer surface of building envelope defines the temperature difference between warm and cold side of building envelope elements and thus the amount of heat loss through building envelope by heat conduction. In this paper such method which sets temperature on the outer surface of building envelope is proposed.

\section{USING WATER - ICE PHASE CHANGE TO DECRASE HEAT FLUX IN BUILDING ENVELOPE}

To set temperature on the outer facade of the building envelope it is proposed to make the outer layer of facade from 
water (water wall). The freezing point of water is $0{ }^{\circ} \mathrm{C}$. If the outdoor air temperature decreases under $0{ }^{\circ} \mathrm{C}$, water on the outer surface of building envelope will start to freeze and use the latent phase change energy. While water freezes the temperature does not change and stays $0{ }^{\circ} \mathrm{C}$. Therefore the temperature difference, which defines heat loss through heat conduction in building envelope, will be lowered. In this case phase change energy of water acts as auxiliary heat source. Water as PCM is chosen because it is easily available and in case of leakage does not harm environment.

Analytically phase change from liquid to solid state is expressed with the following differential equation:

$$
\frac{\mathrm{T}_{\mathrm{fr}}-\mathrm{t}_{\mathrm{am}}}{\left(\frac{\mathrm{x}}{\mathrm{k}_{\mathrm{s}}}\right)+\left(\frac{1}{\mathrm{~h}_{\mathrm{am}}}\right)}=\frac{\mathrm{T}_{1}-\mathrm{T}_{\mathrm{fr}}}{\left(1 / \mathrm{h}_{1}\right)}+\frac{\rho_{\mathrm{s}} \mathrm{h}_{\mathrm{sf}} \mathrm{dx}}{\mathrm{d} \tau}
$$

The phase change from liquid to solid state can be seen in Figure 2.

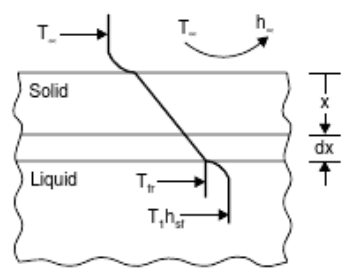

Fig.2. Phase change from liquid to solid state [12]

An experimental rig was built and heat flux measurements were done to confirm that using water as outer layer of building envelope in cold climate decreases heat losses through building envelope.

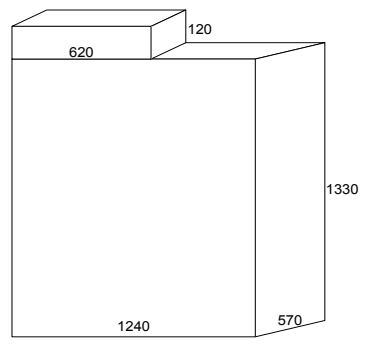

Fig.3. Setup of the experimental rig

The experimental rig consists of an extruded polystyrene box (50 mm wall thickness). Inside of the box is heated by electrical heater. On one half on the top of the box an insulated container filled with water is placed (see Fig.3.).
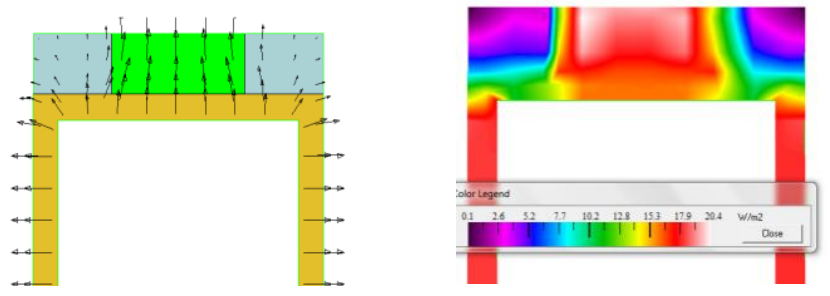

a

b

Fig. 4. Results of heat flux simulation
The experimental rig is much smaller than real life building envelope elements. It is important that measured values are not influenced by the size of the experimental rig. Therefore, heat flux modeling with two-dimensional conduction heat-transfer analysis software were done. Microsoft WindowsTM based computer program THERM 7 Beta developed at Lawrence Berkeley National Laboratory (LBNL) was used for heat flux simulations. Because of the small size of the experimental rig it is important that measurements are not affected by thermal bridges and not perpendicular heat fluxes caused by the shape of experimental rig. The results of heat flux simulation showed that at the point where the heat flux is measured there is no effect of nonperpendicular heat flux or thermal bridges (see Fig.4).

The experimental rig was placed outdoors in real climatic conditions. Experiment and measurements were done in Riga (the capital of Latvia). The measurement was conducted from February 6 to February 13, 2012. The total measurement time was 176 hours (7days 8h). Measurement length was determined by the duration of the water freezing process. It was necessary to ensure that the entire water layer will freeze during measurement. Measurements of completely frozen water wall construction were also carried out. Measurements were done with 10 minute time step.

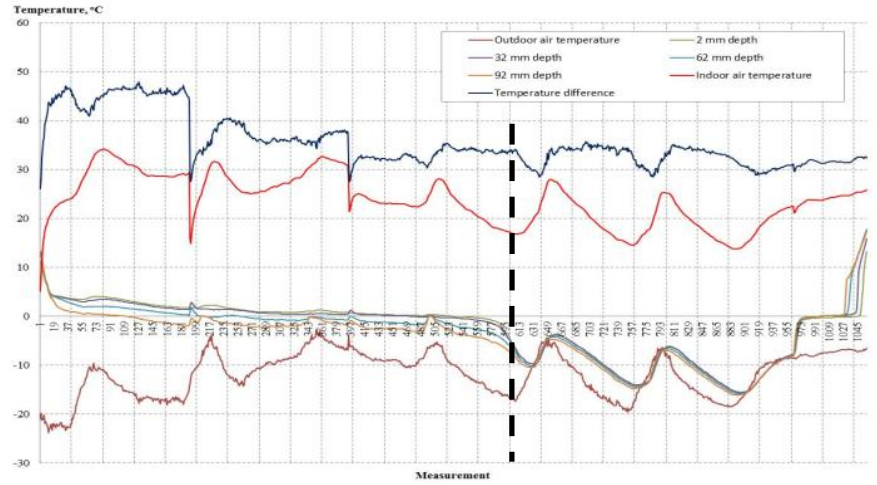

Fig.5. Outdoor and water temperatures during measurements

During measurement outdoor air temperature was in range from $-23.9{ }^{\circ} \mathrm{C}$ to $-2.5{ }^{\circ} \mathrm{C}$. Cyclic overnight outdoor air temperature changes can be seen. An electric heater with a constant power was chosen to maintain room air temperature. Therefore cyclic overnight temperature changes in the observed room air temperature can be seen.

Changes in water temperature show that the water is freezing from the upper layers and gradually freezes into deeper water layers. At the given outdoor temperatures 56 hours were required for the entire water layer to freeze (vertical water freezing speed $-2.143 \mathrm{~mm} / \mathrm{h}$ ).

After all the water layer is frozen, the ice temperature at different depths converges and no more latent heat is used. At the end of measurement (beginning from 960th measurement point) electric water heater was turned on and the ice was melted.

Heat flux densities through the reference wall and water wall during the measurement are shown in Figure 6. The measurement results demonstrate that the heat flow in building 
envelope with the water wall is significantly lower than in the reference wall (a wall without water on the outer surface), which shows that the water phase transition latent energy can be used to reduce the heat conduction losses through the building envelope in cold climates.

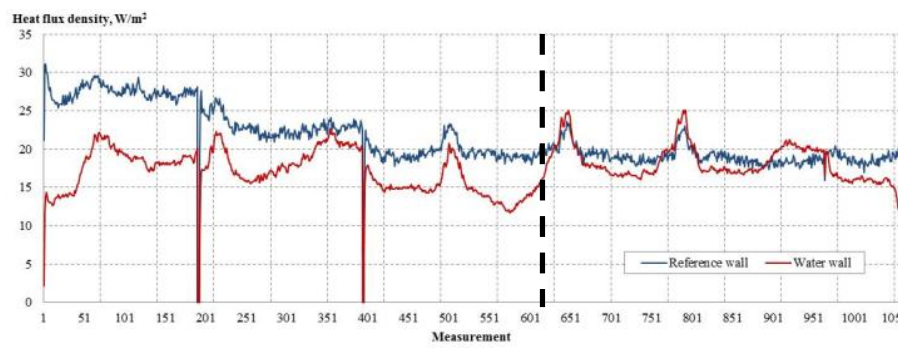

Fig.6. Heat flux density measurement results

After all the water is frozen (black dashed vertical line in Figure 6.) heat flow in the reference wall and water wall converge, because all the phase transition latent energy is used.

The total water wall heat transfer coefficient, which includes the water layer and the use of latent energy of phase transition for reducing heat conduction losses was calculated. By doing this analysis it was concluded how the total heat transfer coefficient of the water wall changes depending on the outdoor temperature. The heat transfer coefficient for wall with no water layer is not dependent on the outdoor temperature and it is constant. For the water wall the total heat transfer coefficient varies depending on the outdoor temperature. The lower the outdoor temperature, the lower the total heat transfer coefficient of the water wall. Results of measurements of the total heat transfer coefficient of the water wall are shown in Figure 7.

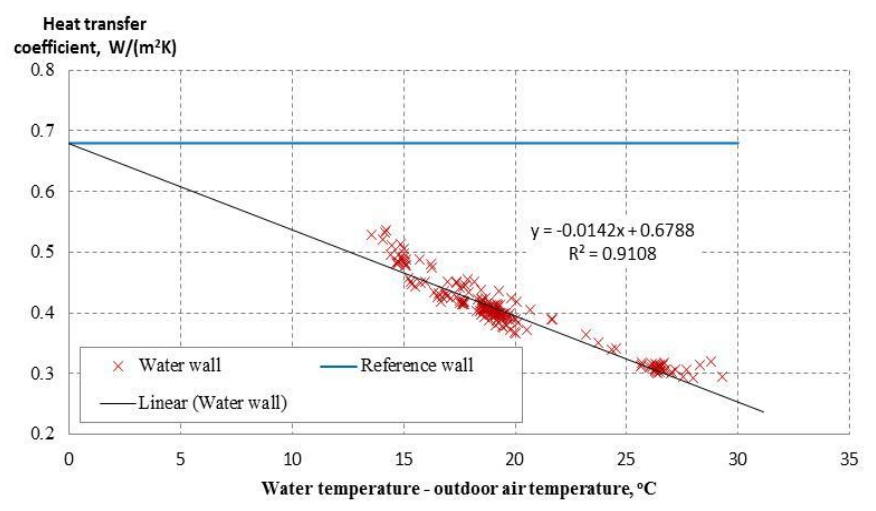

Fig. 7. The total heat transfer coefficient of water wall depending on outdoor air temperature

The figure shows the dependence of the total heat transfer coefficient of the water wall on outdoor air temperature. The $\mathrm{X}$-axis shows water temperature and outdoor air temperature difference instead of the room air and outdoor air temperature difference. This is done to show that, if the temperature difference is $0{ }^{\circ} \mathrm{C}$, the total heat transfer coefficient of water wall is the same as for the reference wall (a wall without water layer on outer surface). The measurement data show very good correlation between the total heat transfer coefficient of water wall and water temperature and outdoor temperature difference. The total heat transfer coefficient of water wall decreases by $0.0142 \mathrm{~W} /\left(\mathrm{m}^{2} \mathrm{~K}\right)$ if outdoor temperature is decreased by one degree. The difference between conventional insulation material with a constant heat transfer coefficient and the water wall, with the heat transfer coefficient being dependent on the outside air temperature can be clearly seen. The proposed technology is used in cold climates, because the lower outdoor air temperatures decrease the total heat transfer coefficient of water wall.

\section{RECOVERING LATENT ENERGY USING LOW POTENTIAL HEAT SOURCE}

If the latent energy of phase change is not recovered then ice is formed on the outer surface of the building envelope. The ice stays on the building envelope until outdoor temperature exceeds $0{ }^{\circ} \mathrm{C}$. While water is melting large amount of energy is used. If energy is not recovered using an auxiliary heat source, then the total energy balance for space heating of the building is the same for building with water wall and without it. The only difference in this case would be shift of peak heating load.

The authors propose to set up a structure on the outer façade of building in which a circulating heat transfer fluid (HTF) could be implemented (see Fig.8). The lost heat energy would be regenerated via natural heat energy sources.

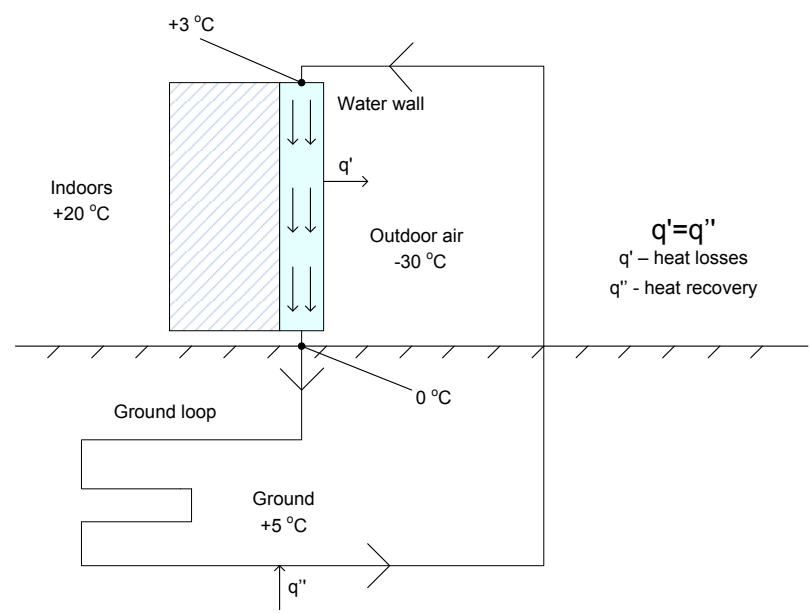

Fig. 8. Schematic interpretation of proposed structure for heat loss reduction

Heat transfer fluid ensures that the temperature on the outer façade of the building remains in a narrow temperature range. In this example we will set the temperature at about 0 ${ }^{\circ} \mathrm{C}$. With the introduction of HTF in the building outer faced, a heat source within the building wall is introduced which insures constant temperature on the outer building façade.

In order to described this newly developed system, as a heat recovery source the ground geothermal energy is used. In this example undisturbed ground temperature in winter Latvian climate conditions is about $6,5^{\circ} \mathrm{C}[6]$.

In the reviewed literature, there was no information about the undisturbed ground temperature and at what depth it could be obtained in Latvia. Since these data are crucial for further heat transfer calculations, the most suitable method to obtain these data was found. In a publication by Florides and 
Kalogirou [7] the ground temperature distribution in various depths and seasons was shown. By constructing a similar graph, the undisturbed ground temperature profile for Latvian climate conditions was constructed. The obtained results can be seen in Fig.9.

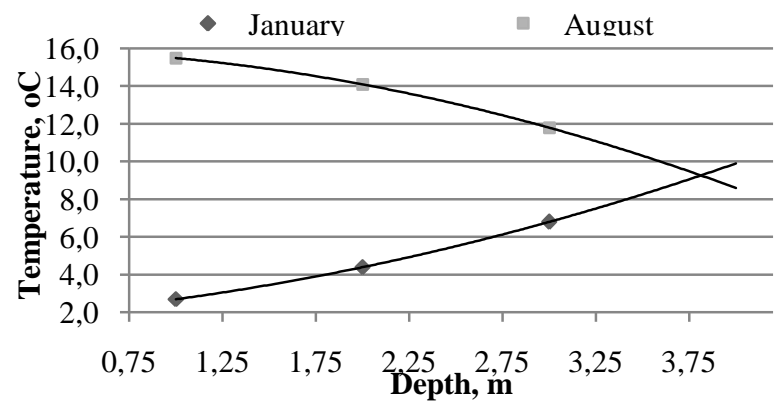

Fig. 9. Ground temperature variation by depth in Gulbene, Latvia [6]

In Fig.7 it can be seen that the undisturbed ground temperature is reached at a depth of about 3,75 meters, but according to study by Florides and Kalogirou, the undisturbed ground temperature is reached at grater depths due to temperature drop velocity decrease with depth, meaning that the rate, at which the ground temperature difference between different seasons at certain depth lowers, decreases also by depth. These are only official data available, so some assumptions have to be made to obtain undisturbed ground temperature and depth at which this temperature is reached.

The model optimization, to determine the most suitable HTF phase change temperature, has to be done. This is very complex process in which such parameters as ambient temperature, natural heat source temperature, various building and heat recovery unit parameters are changed in order to achieve the most efficient system operation conditions for the given situation. For these application purposes water as a HTF was chosen. Water has a phase change temperature in the desired range and water cycle is one of the simplest natural cycles on Earth, therefore when water is used in an application and HTF leakage into surrounding environment occurs, water represents almost no potential threats to the ecosystem, which is not the case for other PCM's. According to Cabaza and Mehling, the best phase change material by far is water [1].

Nevertheless water may not be suitable for this type of application. As stated by Akyurt, Zaki and Habeebullah [8], water, similarly to other PCM's, posses a phenomena called sub-cooling, which means that actual crystallization of water occurs at about $-4^{\circ} \mathrm{C}$, which could lead to an error in calculations. There is also the problem with water solidification, which has been studied in researches dealing with transient solidification of liquids in pipes [9]. According to the research if no modifications to the pipes are done, the water flowing in the tube freezes from the inner tube walls towards the center of the tube. Freezing stops if one of the following conditions is reached. The tube can freeze completely making further water flow impossible. Or an equilibrium state where further freezing of pipe with definite length and constant heat flux is avoided. One of the limiting factors is ice, which in metal pipes acts as an insulator. To avoid the ice clogging in the system appropriate methods and conditions need to be studied.

Depending on the ambient temperature only a portion of latent heat available in the heat transfer fluid will be used. This can be achieved by varying circulation velocity through the system.

- The proposed model depends on tree main parts:

- Heat losses through the building outer wall façade,

- A unit which controls the heat transfer fluid flow through the whole system,

- Heat recovery unit, which ensures heat regeneration from natural heat energy sources.

Heat loss through the building envelope must be the same as heat recovery from the heat recovery unit, therefore an energy balance equation must be established:

$$
Q_{h . l .}=Q_{h . r}
$$

Energy balance (5) must be provided at all times, to guarantee efficient system operation. At the first stage system is modeled to fit certain ambient conditions. In Latvian winter climate conditions, the temperature difference between ambient and room temperature could be as high as $50 \mathrm{~K}$, therefore authors decided to model the system behavior in temperature range $-30{ }^{\circ} \mathrm{C}$ to $+30{ }^{\circ} \mathrm{C}$.

The main objective of this paper is to find out if the efficiency of this system is sufficient enough to be implemented in every-day use, specifically in winter season.

\section{Methodology}

The heat flux calculations are divided in two different sections. In the first section a model describing heat losses in winter conditions is created and in the second section a model describing heat gains in summer is created. In the next step information about model operation in different temperature regimes is gathered and a graph showing temperature changes depending on the ambient temperature changes is constructed. From this an equation describing the model operation in various ambient temperatures can be obtained and it can be used to theoretically describe the model operation in various locations in Latvia based on actual data.

The heat flux from the wall to the ambient can be calculated as shown in:

$$
Q_{F}=q \cdot S
$$

This equation is true, if the heat flux density $q$ in the whole area is constant. From the equation 1 it can be seen, that the heat flux density depends on the temperature difference between ambient and room temperature, and since there are two different temperature regimes on the wall, different heat fluxes densities need to be calculated. One area is described with a constant temperature. In this area latent heat of the heat transfer fluid is transferred to the surrounding air in constant temperature. In the other area sensible heat of the heat transfer fluid is released. When releasing the sensible heat it takes much less energy to change its temperature by $1 \mathrm{~K}$, therefore 
temperature fluctuations in this area are observed. In order to get precise estimation of heat losses the, area of each temperature regime has to be calculated. Another consideration that needs to be taken into account is ambient air temperature fluctuations. If we set the system parameters in such way that regardless of the ambient temperature system uses fixed amount of latent heat stored in the heat transfer fluid, then by increasing ambient temperature, the circulation velocity of heat transfer fluid through the system must be decreased. This means that by circulating the heat transfer fluid through the heat recovery loop more heat energy will be gained, thus raising the temperature of heat transfer fluid higher, then the initially set temperature. Taking all assumptions into consideration we get a dynamic system which is dependent on ambient temperature and the portion of latent heat used. If the ambient temperature rises, the heat transfer fluid circulation velocity decreases and the initial heat transfer fluid temperature rises. If the portion of latent heat used is decreased, the heat transfer fluid circulation velocity increases and the heat transfer fluid temperature decreases.

To calculate total heat losses from the wall, heat losses from both sections at any given time need to be calculated and the proportion of different temperatures on the wall need to be estimated. The sensible heat stored and released to the ambient can be described through the following:

$$
\mathrm{k} \cdot\left(\frac{\mathrm{t}_{\mathrm{out}}+\mathrm{t}_{\mathrm{h}}}{2}-\mathrm{t}_{\mathrm{am}}\right) \cdot \mathrm{S}_{1}=\dot{\mathrm{m}} \cdot \mathrm{c} \cdot\left(\mathrm{t}_{\mathrm{out}}-\mathrm{t}_{\mathrm{kr}}\right)
$$

On the left side of the equation a process of heat release to the ambient is described. On the right side of the (7) a process which describes the heat stored in the heat transfer fluid is shown.

For the part where latent heat is released a similar equation can be written:

$$
\mathrm{k} \cdot\left(\mathrm{t}_{\mathrm{h}}-\mathrm{t}_{\mathrm{am}}\right) \cdot \mathrm{S}_{2}=\dot{\mathrm{m}} \cdot \mathrm{h} \cdot \mathrm{x}
$$

Latent heat storage in the heat transfer media is described on the right side of this equation. By changing the $\mathrm{x}$ value, the amount of latent heat utilized in the heat transfer process can be changed. By expressing $\dot{\mathrm{m}}$ from equations (7) and (8) and later equating them, the area ratio $\frac{\mathrm{s}_{2}}{\mathrm{~S}_{1}}$ can be determined. Since both areas have the same length, the ratio $\frac{s_{2}}{s_{1}}$ can be abbreviated by its length, and in the result we get (9), which is marked as $\beta$ :

$$
\frac{\mathrm{l}_{2}}{\mathrm{l}_{1}}=\frac{\left(2 \mathrm{t}_{\mathrm{am}}-\mathrm{t}_{\text {out }}\right) \cdot(\mathrm{h} \cdot \mathrm{x})}{2 \mathrm{c} \cdot \mathrm{t}_{\mathrm{out}} \cdot \mathrm{t}_{\mathrm{am}}}=\beta
$$

For initial purposes, the (9) is modified in such way, that only a HTF with phase change temperature of $0^{\circ} \mathrm{C}$ can be calculated for application in the modified wall.

Taking into account that the total wall height is predetermined, the height of each area can be determined by solving this equation system:

$$
\left\{\begin{array}{c}
\frac{\mathrm{l}_{2}}{\mathrm{l}_{1}}=\beta \\
\mathrm{l}_{1}+\mathrm{l}_{2}=\mathrm{a}
\end{array}\right.
$$

By knowing the height of each area it is possible to calculate the heat fluxes of areas with different temperatures and by adding these two separate heat fluxes up, the total heat flux of the whole wall is calculated.

For summer months the calculations are simplified, since there is only one phase without any phase change present. To calculate the heat flux in summer season, (6) can be used.

Heat recovery and heat dumping is accomplished by heat recovery loop, which can be placed in the ground or open water reservoir. In this research we simulated heat recovery in the winter seasons and heat dumping in summer seasons using a vertical ground heat exchanging loop thus utilizing geothermal heat energy which is a renewable energy source with almost no additional running costs.

There are many factors to be considered modeling a heat exchange through a ground heat exchanger which will not be discussed here as the main objective of this study is to evaluate wall performance in different temperature regimes. To calculate heat transfer in the ground heat exchanger, (11) can be used:

$$
\mathrm{R}_{\mathrm{gr}}=\mathrm{R}_{\mathrm{bh}}+\mathrm{R}_{\mathrm{p}}
$$

The total ground heat exchanger thermal resistance consists of the borehole thermal resistance and the heat exchange pipe thermal resistances.

The borehole thermal resistance can be calculated according to (12) [10]:

$$
R_{\text {bor. }}=\frac{1}{\beta_{0}\left(d_{\text {bor }} / d_{\text {pipe }}\right)^{\beta_{i}} \lambda}
$$

The $\beta$ is a coefficient that is obtained by studying full scale experimental models. It depends on the heat exchange pipe alignment in the borehole.

The heat exchange pipe thermal resistances can be calculated according to the (13), which is known as the linear thermal resistance:

$$
\mathrm{R}_{\mathrm{p}}=\frac{1}{2 \pi \lambda} \ln \frac{\mathrm{d}_{\text {out }}}{\mathrm{d}_{\mathrm{in}}}
$$

When the total ground thermal resistance is obtained, the heat transfer coefficient can be calculated. Inserting the corresponding variables in the equation 1, the linear heat flux density $\mathrm{qL}$ is calculated. Linear heat flux density describes how much heat within given temperature difference can be obtained or dumped in the ground from one meter of vertical ground heat exchanger, thus it is possible to calculate total length of heat exchanger which is needed to fully recover the heat which has been lost to the ambient. 
The modeling of heat transfer in the summer months is similar to winter conditions. The equations are the same, only in these conditions there is no phase change of the heat transfer fluid thus simplifying the heat transfer calculations.

The next step is to model system behavior in different temperature regimes and obtain an equation which describes the system operation in different ambient temperatures. For this purpose several temperatures were chosen in which the parameters of system were varied to obtain smoother operation of the system.

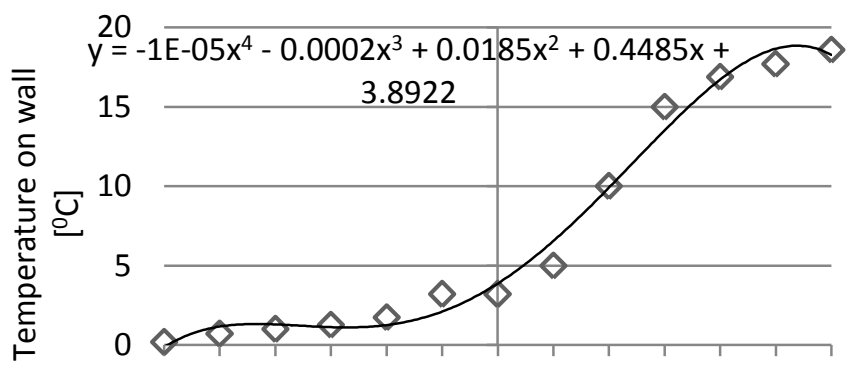

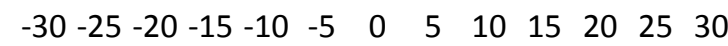
Outdoor air temperature $\left[{ }^{\circ} \mathrm{C}\right]$

Fig. 10. Temperature regimes on the wall depending on the ambient temperature

The chosen values can be seen in Table I. From these values it is possible to model a graph which shows the temperature regimes on the wall depending on the ambient temperature and obtain an equation, which describes this relation (see Fig.10). This equation will be used to compare heat loss in different cities in Latvia using the temperature date provided by the LVĢMC.

TABLE I. SYSTEM OPERATION IN DIFFERENT TEMPERATURE REGIMES

\begin{tabular}{ccccccc}
\hline $\mathbf{t}_{\mathbf{a m}}$ & $\mathbf{t}_{\mathbf{w . w a l l}}$ & $\mathbf{x}$ & $\mathbf{t}_{\text {beg }}$ & $\mathbf{t}_{\text {out }}$ & $\mathbf{t}_{\mathbf{g r}}$ & $\dot{\boldsymbol{m}}$ \\
\hline-30 & 0.19 & 0.30 & 0 & 3.3 & 6.5 & 0.04 \\
\hline-25 & 0.72 & 0.20 & 0 & 5.9 & 6.5 & 0.04 \\
\hline-20 & 1.00 & 0.15 & 0 & 6.4 & 6.5 & 0.04 \\
\hline-15 & 1.27 & 0.10 & 0 & 6.4 & 6.5 & 0.04 \\
\hline-10 & 1.75 & 0.05 & 0 & 6.4 & 6.5 & 0.04 \\
\hline-5 & 3.2 & 0 & 0 & 6.4 & 6.5 & 0.04 \\
\hline 0 & 3.2 & 0 & 0 & 6.4 & 6.5 & 0.02 \\
\hline 20 & 16.9 & 0 & 19 & 14.8 & 7 & 0.39 \\
\hline 25 & 17.7 & 0 & 22 & 13.5 & 7 & 0.21 \\
\hline 30 & 18.6 & 0 & 27 & 10.2 & 7 & 0.11 \\
\hline
\end{tabular}

There must be a temperature difference between the room temperature and the ambient in order to calculate the heat loss through the building envelope. The room temperature is calculated by the (14):

$$
\mathrm{t}_{\text {room }}=0,1 \mathrm{t}_{\text {out }}+21
$$

This equation shows that the room temperature depends on the ambient condition. The room temperature is set as follows: when ambient temperature is $-30{ }^{\mathrm{O}} \mathrm{C}$, the room temperature is $18{ }^{\mathrm{O}} \mathrm{C}$ and when ambient temperature is $+30{ }^{\mathrm{O}} \mathrm{C}$ the room temperature is $24{ }^{\mathrm{O}} \mathrm{C}$. By finding the linear relation between these two temperatures, room temperature at any ambient temperature can be determined. Finally by using equation 6 it is possible to determine the total heat loss.

\section{RESULTS}

The main objective of this study was to analytically examine the operation of proposed innovative heat loss reduction system in different Latvian climate conditions and compare the heat loss to those which were demonstrated by the wall that has not been fitted with the innovative system. In order to do so, an equation which describes the operation of the model in different temperature regimes is defined. Since the minimal temperature on the outer wall is strictly defined regardless of the ambient conditions, it is expected that the heat loss would also be limited by highest value. Where as in the case where there are no additional structures that are limiting the heat loss threw the building envelope, the heat loss would be strongly influenced by the ambient temperature fluctuations.

The results are summarized in a graph which shows heat loss for both cases - with and without the transient HTF (see Fig. 10). Heat flux values above 0 represent heat that is leaving the building, negative heat flux values represent heat that is penetrating into the building. The result discussion can be divided in two different parts, one for the winter season and one for the summer season. In total there were six graphs constructed showing the comparison of heat loss through wall with and without fitted system in different locations and years in Latvia. In addition total heating, cooling and heating loads in winter heating season were shown. Winter heating season in Latvia starts in 1st of October and lasts till April 15th of next year. An example of heating and cooling load comparison throughout the year is shown in Table II.

TABLE II. ENERGY AMOUNT NEEDED TO PROVIDE THE PRE-SET ROOM TEMPERATURE IN JELGAVA 2006

\begin{tabular}{ccc}
\hline & $\begin{array}{c}\text { Without } \\
\text { modifications }\end{array}$ & $\begin{array}{c}\text { With } \\
\text { modifications }\end{array}$ \\
\hline Heating, MWh & 4.08 & 3.58 \\
\hline Cooling, kWh & -29.86 & 0.00 \\
\hline Heating season & 3.08 & 2.40 \\
\hline $\begin{array}{c}\text { Reduction in } \\
\text { heating season, \% }\end{array}$ & & 22.1 \\
\hline
\end{tabular}

It can be pointed out that wall temperature lies in strict, pre defined temperature regime. Since water is chosen as the HTF, the minimal temperature on the outer wall is set at $0{ }^{\circ} \mathrm{C}$, but maximal temperature, is $20{ }^{\circ} \mathrm{C}$. The yearly temperature fluctuation on the wall is reduced by about $65,5 \%$.

From the Fig. 10 it can be seen that the maximum heat losses in the most sub-zero temperature conditions do not exceed the average $600 \mathrm{~W}$ per hour, whereas in case without any modifications average heat losses can exceed an average value of $1400 \mathrm{~W}$ per hour, therefore it is possible to observe heat loss reduction as high as $57 \%$. A total of $12.3 \%$ of heat loss reduction throughout the year is achieved. In the authors opinion it is not correct to evaluate the heating load reduction 
in one year period of time in this case. By examining heat loss graph in Fig. 10, it can be seen that in summer months the wall with installed modifications presents a cooling potential, which in total heating and cooling load balance is calculated as heating load. Therefore in winter season it would be more accurately to show heating load reduction in winter heating season. From Table III it can be seen that the heating load reduction in the winter heating season in Jelgava 2006 is about $22.1 \%$. Although this figure is strongly influenced by the average yearly temperature and its seasonal fluctuations, the average heat losses in different cities and years in Latvia were decreased on average by $20 \%$, which is considered as a relatively high reduction rate (see Table III).

TABLE III. TOTAL HEAT LOAD REDUCTION IN HEATING SEASON

\begin{tabular}{cccc}
\hline City & Year & Reduction, \% & Reduction, kWh \\
\hline Gulbene & 2002 & 24.3 & 819.39 \\
\hline Jelgava & 2006 & 22.1 & 680.23 \\
\hline Dobele & 2007 & 19.0 & 556.37 \\
\hline Riga & 2008 & 14.4 & 392.76 \\
\hline Ventspils & 2008 & 12.5 & 328.01 \\
\hline Priekuli & 2009 & 21.5 & 690.69 \\
\hline
\end{tabular}

In summer season with the modifications made to the wall there is no need for a cooling load in contrast with the wall where there are no modifications made. From the Fig. 11 it can be seen that between hours 3963 and 5378, cooling loads are needed to remove the solar heat gains.

In research it was concluded that the system operation is feasible in the temperature range under $0{ }^{\circ} \mathrm{C}$ and above $20{ }^{\circ} \mathrm{C}$ for Latvian climate conditions. These limitations are because of the natural heat source temperatures. In this case the average temperature of the ground in winter season is estimated at about $6.5{ }^{\circ} \mathrm{C}$, and in the summer season the average ground temperature is $7{ }^{\circ} \mathrm{C}$, hence the minimal average temperature difference between the HTF and the heat source is about $10{ }^{\circ} \mathrm{C}$, but this value can vary place by place. If temperature difference decreases, the linear heat flux density between HTF and the ground heat source also decreases, which means, that a larger heat exchanger is needed to achieve the same heat recovery.

The next step of this research includes development of a prototype water wall system in real climatic conditions. This will lead to a better understanding of possible weak points in the operation of the whole system and will show how the system operates under real climatic conditions.

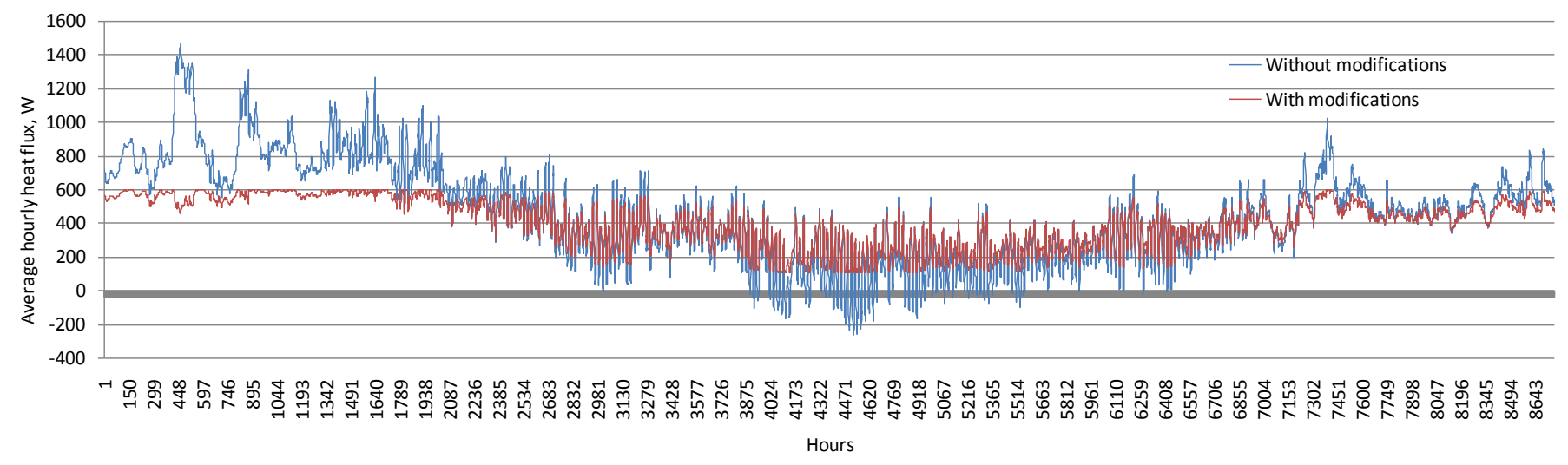

Fig. 11. Heat loss comparison in the case with and without the proposed system in Jelgava 2006

\section{REFERENCES}

[1] H. Mehling, L.F. Cabeza. Heat and cold storage with PCM: An up to date introduction into basics and applications. Berlin : Springer, 2008.

[2] Jiang He, Akira Hoyano. Experimental study of cooling effects of a passive evaporative cooling wall constructed of porous ceramics with high water soaking-up ability. Yokohama : Elsevier, 2009.

[3] Data base from State Ltd "Latvian Environment, Geology and Meteorology Centre", www.meteo.lv

[4] D. Mumovic, M. Santamouris. Sustainable Building Design and Engineering : An Integrated Approach to Energy, Health and Operational Performance. London: Earthscan , 2009 . eISBN: 9781849770279.

[5] A, LVS EN ISO 6946:2008. Ēku būvkomponenti un būvelementi. Siltumpretestība un siltumapmaiņas koeficients. Aprēķināšanas metodika.
[6] Meteorologijas, Latvijas Vides Ģeolog̣ijas un. Temperatūras sadalījums zem dabiskās veǵetācijas virsmas.

[7] G. Florides, S. Kalogirou. Ground heat exchangers-A review of systems, models and applications. Nicosia : Elsevier, 2007.

[8] M. Akyurt, G. Zaki, B. Habeebullah. Freezing phenomena in ice-water systems. Energy Conversion and Management. 2002. gada, Sēj. 43, 14.

[9] R. Conde, M.T. Parra, F. Castro, J.M. Villafruela, M.A. Rodriguez, C. Mendez. Numerical model for two - phase solidification problem in a pipe. Valladolid : Elsevier, 2004.

[10] M. H. Sharqawy, E. M. Mokheimer, H. M. Badr. Effective pipe-toborehole thermal resistance for vertical ground heat exchangers. Geothermics. 2009. gada.

[11] M. Maerefat, A.P. Haghighi. Natural cooling of stand-alone houses using solar chimney and evaporative cooling cavity. Tehran : Elsevier, 2010 .

[12] C.P. Kothandaraman, Fundamentals of Heat and Mass Transfer, New Age International, Daryaganj, Delhi, IND, 2006. - 729 p.

\section{Creative Commons Attribution License 4.0 (Attribution 4.0 International, CC BY 4.0)}

This article is published under the terms of the Creative Commons Attribution License 4.0

https://creativecommons.org/licenses/by/4.0/deed.en_US 